\title{
Sexually Dimorphic Polypeptides in Developing Antennal Sensory Neurons of an Insect
}

\author{
Timothy G. Kingan ${ }^{\mathrm{a}}$ and John G. Hildebrand \\ Arizona Research Laboratories, Division of Neurobiology, University of Arizona, Tucson, Arizona 85721
}

\begin{abstract}
Many insects have sexually dimorphic antennae with sensilla peculiar to one sex specialized to detect sex pheromones released by the other sex. In the moth Manduca sexta, the axons of receptor cells in the male-specific sensilla as well as those common to both sexes terminate in the antennal lobes of the brain. We have used 2-dimensional electrophoresis $(2 D E)$ to study some of the proteins that are produced by sensory receptor cells in developing antennae and transported through their axons to the brain.

Extracts of antennal nerves from mature male and female $M$. sexta yield nearly identical $2 \mathrm{DE}$ patterns of proteins after staining or fluorography. Gels prepared from antennal nerves of developing animals, however, exhibit a sexual dimorphism in the quantitative pattern of at least 2 classes of proteins. One class consists of four $49 \mathrm{kDa}$ proteins of similar charge, designated $49 a, 49 b, 49 c$, and $49 d$ in order of decreasing mobility on nonequilibrium $\mathrm{pH}$ gradient electrophoresis gels. The total amount and apparent rate of synthesis of $49 \mathrm{~b}$ and 49d are ca. 4- to 7-fold greater in antennal nerves of developing males than in those of females. Protein $49 \mathrm{c}$ is comparably enriched in female antennal nerves, while $49 \mathrm{a}$ is enriched ca. 1.2-fold in females. The second class consists of a single polypeptide of $24 \mathrm{kDa}$, which is nearly undetectable in silver-stained gels but was shown to be ca. 9-fold enriched in males by fluorography.
\end{abstract}

At the end of adult development, male and female moths have similar patterns of the $\mathbf{4 9} \mathrm{kDa}$ polypeptides, and synthesis of the $24 \mathrm{kDa}$ polypeptide is reduced to nearly undetectable levels. The patterns of sexual dimorphism thus appear to be associated with the growth and maturation of antennal sensory axons into the antennal lobes. Biosynthesis of the $24 \mathrm{kDa}$ polypeptide was nearly undetectable in antennal lobes or fragments of antennal nerves incubated in vitro with radiolabeled methionine. The 49 and $24 \mathrm{kDa}$ polypeptides appear to belong to separate classes of rapidly transported proteins. The $24 \mathrm{kDa}$ polypeptide is among the

\footnotetext{
Received July 8, 1988; revised Oct. 17, 1988; accepted Nov. 7, 1988.

We thank Norla Antinoro, Chip Hedgcock, and Ruth Montague for photographic assistance, Peggy Randolph and Deborah Sakiestewa for insect rearing, and Drs. J. Buckner and J. Svoboda of the USDA for supplying Manduca sexta eggs. We are grateful to Robin Humphreys and Dr. David Sammons for use of the Bioimage system and to Will Korn and Art Papier for technical assistance in the early phases of this study. This research was supported by NSF grants BNS 83-12769 and 86-41145 and by a grant from the Monsanto Company.

Correspondence should be addressed to Dr. John G. Hildebrand, $\Lambda$ RL Division of Neurobiology, 611 Gould-Simpson Science Bldg., University of Arizona, Tucson, AZ 85721 .

a Present address: Peptide Design, 1237.1 Middlebrook Road, Germantown, MD 20874

Copyright $@ 1989$ Society for Neuroscience $0270-6474 / 89 / 061951-10 \$ 02.00 / 0$
}

most rapidly transported proteins; it is found exclusively in a particulate fraction and is associated with plasma membrane but apparently not mitochondria. The $49 \mathrm{kDa}$ polypeptides are found in both the particulate and soluble fractions; the more basic $49 a$ and $49 \mathrm{~b}$ are enriched in the particulate fraction, while the more acidic $49 \mathrm{c}$ and $49 \mathrm{~d}$ are enriched in the soluble fraction.

Gender-specific behaviors and reproductive functions of many animals have anatomical correlates in their CNS. Such sexual dimorphism, which can be manifested as differences in cell numher, size, or extent of arborization in certain brain nuclei, underlies sex-specific behavior in the adult (Arnold and Gorski, 1984). In vertebrates, gonadal steroids act perinatally and neonatally to control the development of sexually dimorphic structures in the brain; much earlier the same steroids regulate the dimorphic development of the reproductive system. Thus, while the gonads themselves are genetically determined, all other sexual dimorphism depends on gonadal secretions.

In many invertebrates sex-specific behaviors have been well documented, but relatively little is known about their cellular or developmental bases in the nervous system. For example, many male moths exhibit species-specific, stereotyped behaviors when exposed to the sex pheromones released by conspecific females. The male moths respond with characteristically patterned, upwind flight in the plume of pheromone in search of a female. The pheromone-detecting sensory cells innervate sensilla in the antenna. Often, as in the sphinx moth Manduca sexta, the antennae are sexually dimorphic, and the pheromonedetecting receptor cells are associated with long, male-specific olfactory hairs on the antenna, the sensilla trichodea (Sanes and Hildebrand, 1976a). The olfactory receptors of antennal sensilla send out axons, up to $2 \mathrm{~cm}$ long, that project through the antennal nerve (AN) and terminate in the antennal lobe (AL) of the brain (for review, see Hildebrand, 1985). It has been shown in $M$. sexta that axons from the trichoid sensilla terminate exclusively in a male-specific synaptic region of the AL, the macroglomerular complex (MGC).

The antennae of moths arise during metamorphic adult development from imaginal disks present in the head of the larva. The sexual dimorphism of the antenna is genetically determincd, so that imaginal disks can be transplanted between sexes to give rise to antennae that are typical of the donor's gender (Schneiderman et al., 1982; Hildebrand, 1985). The structure of the AL, however, is not genetically determined: The MGC characteristic of the normal male develops only in an AL innervated by sensory axons from a male antenna. Indeed, if a female receives a male antennal disk by transplantation, she 
develops an MGC in the AL innervated by the AN from the grafted antenna (Schneiderman et al., 1982; Hildebrand, 1985).

Such transplantation experiments have revealed that development of the MGC depends upon direct innervation of the AL by male-specific antennal axons. Thus, the MGC does not develop if the male AN fails to contact the brain or does so at sites other than the AL. This requirement for intimate interaction between the $\mathrm{AN}$ and the $\mathrm{AL}$ raises the possibility that one or more nondiffusible substances, synthesized in male antennal sensory neurons and transported along their axons, may influence the formation of the MGC. Likely candidates for this role would be polypeptides unique to, or highly enriched in, male ANs. We have pursued this possibility by comparing the total and axonally transported polypeptides in ANs of developing male and female $M$. sexta by 2-dimensional electrophoresis (2DE). A preliminary account of some of these results appeared previously (Kingan and Hildebrand, 1983).

\section{Materials and Methods}

\section{Animals}

Manduca sexta (Lepidoptera: Sphingidac) wcre rcarcd at $26^{\circ} \mathrm{C}$ and ca. $60 \%$ relative humidity on artificial diet (modified from that of Bell and Joachim, 1976) in a long-day photoperiod (17 hr light: $7 \mathrm{hr}$ dark). Insects were staged according to previously published criteria (Sanes and Hildebrand, 1976a; Tolbert et al., 1983). Adult development occurs over 18 "stages," corresponding to ca. 21 d.

\section{Radiolabeling of $A N$ proteins}

Proteins in the ANs of developing moths were labeled with $\mathrm{L}^{-35} \mathrm{~S}-\mathrm{me}$ thionine by in situ and in vitro procedures.

In situ labeling. ${ }^{35} \mathrm{~S}-M e t h i o n i n e ~(480-2000 \mu \mathrm{Ci},>1000 \mathrm{Ci} / \mathrm{mmol}, \mathrm{Du}$ Pont, NEN Research Products) was dried under reduced pressure in a vacuum centrifuge (Savant Instruments) and dissolved in one-tenth volume of saline solution $150 \mathrm{~mm} \mathrm{NaCl}, 3 \mathrm{~mm} \mathrm{KCl}, 3 \mathrm{~mm} \mathrm{CaCl}, 10$ mM $N$-tris(hydroxymethyl)methyl-2-aminoethanesulfonic acid (TES), and $25 \mathrm{~mm}$ sucrose, $\mathrm{pH}$ 6.9] or in a similar volume of methionine-free Grace's insect tissue culture medium (Grace, 1962; GIBCO). Animals were anesthetized by chilling on ice for $30 \mathrm{~min}$ and prepared for injection by cutting a small piece of pupal cuticle covering the developing adult antenna. Needles for injection were prepared from glass capillary tubing with a micropipet puller. Volumes of $0.3-0.4 \mu \mathrm{l}$, containing ca. $50 \mu \mathrm{Ci}$ radioisotope were pressure-injected into the lumen of the antenna by means of a syringe-pump (Harvard Apparatus, model 935) or a pressure injector (Picospritzer, General Valve Corp.). The excised pupal cuticle was replaced and sealed in place with wax (myristic acid). Animals were maintained under normal growth conditions for 0.5-3 d, after which they were again anesthetized on ice for dissection. The brain with the attached AN ipsilateral to the injection site (intracranial segment of the AN only, ca. $2 \mathrm{~mm}$ in length) was removed and placed in a drop of physiological saline. The AL was separated from the rest of the brain after breakage of the sheath overlying the brain with fine forceps. The AN and AL were processed together, or they were separated by cutting the AN at its entrance into the AL. In the latter case, the AN and AL were placed in different glass homogenizers and held on ice. Tissue was then prepared for electrophoresis or for subcellular fractionation prior to electrophoresis (see below).

In vitro labeling. Radiolabeled methionine was dried as described above and redissolved in sterile methionine-free Grace's medium. Brains with attached AN were removed from developing animals and placed in a drop of methionine-free Grace's medium for $15 \mathrm{~min}$. They were then transferred to $50 \mu \mathrm{l}$ Grace's medium containing ${ }^{35} S$-methionine $(50 \mu \mathrm{Ci},>1000 \mathrm{Ci} / \mathrm{mmol})$ and incubated in a hanging drop for $5 \mathrm{hr}$. The brains were then transferred to medium without radiochemical and rinsed for $15 \mathrm{~min}$. The AN was then separated from the AL and placed in a glass microhomogenizer in preparation for extraction and electrophoresis.

\section{Subcellular fractionation}

Two procedures were used for tissue fractionation. For preparation of total particulate and soluble fractions, ANs and ALs were disrupted in a glass microhomogenizer at $0^{\circ} \mathrm{C}$ in buffered medium containing protease inhibitors of the following composition (modified from Shorr et al., 1981): $10 \mathrm{~mm}$ Tris- $\mathrm{HCl}, 2.5 \mathrm{~mm}$ EDTA, $2.5 \mathrm{~mm}$ EGTA, $0.1 \mathrm{~mm}$ benzethonium chloride, $1 \mathrm{~mm}$ benzamidine, $100 \mu \mathrm{g} / \mathrm{ml}$ Bacitracin, 5 $\mu \mathrm{g} / \mathrm{ml}$ soybean trypsin inhibitor, and $2 \mu \mathrm{g} / \mathrm{ml}$ leupeptin, $\mathrm{pH} 7.4$ (all reagents obtained from Sigma Chemical Co.). The homogenate was separated into soluble and particulate fractions by centrifugation at $4^{\circ} \mathrm{C}$ for $6.9 \times 10^{6} \mathrm{~g}_{\mathrm{av}}$ min (Beckman SW 50.1 rotor, 35,000 rpm, $60 \mathrm{~min}$ ). The supernatant (soluble) fraction was decanted and held on ice, and the pellet (particulate fraction) was dried by lyophilization. To precipitate proteins in the soluble fraction, cold $\left(-20^{\circ} \mathrm{C}\right)$ acetone $(4 \mathrm{vol})$ was added with mixing. The resulting precipitate was isolated by centrifugation, washed once with $80 \%$ acetone, and dried briefly in the vacuum centrifuge. The dried particulate and soluble fractions were stored at $-80^{\circ} \mathrm{C}$ no longer than $24 \mathrm{hr}$ prior to analysis.

For fractionation of total membranes, whole brains or brains lacking optic lobes and subesophageal ganglia (in either case, with ANs and ALs still attached) were disrupted in a Potter-Elvejehm homogenizer in $5 \mathrm{~mm}$ Tris $\cdot \mathrm{HCl} / 0.32 \mathrm{M}$ sucrose, $\mathrm{pH} 7.4$, with 30 strokes of the rotating Teflon pestle (Polyscience Corp. homogenizer, model PSC10, lowest setting) in $1 \mathrm{~min}$ at $0^{\circ} \mathrm{C}$. The homogenate was centrifuged at $800 \times g$ for $10 \mathrm{~min}$ (Sorvall SS-34 rotor), and the pellet was resuspended in Tris/ sucrose and centrifuged as above. The supernatant fractions were pooled and membranes pelleted as above for total particulate material (Beckman SW 50.1 rotor, $35,000 \mathrm{rpm}, 60 \mathrm{~min}$ ). The supernatant fluid was removed and retained for analysis. The pellet was resuspended in a small volume of $5 \mathrm{~mm}$ Tris $\cdot \mathrm{HCl} / 0.32 \mathrm{~m}$ sucrose, $\mathrm{pH} 7.4$, and layered onto a discontinuous sucrose gradient containing layers of $20,26,31$, 37,45 , and $55 \%$ sucrose (Lorenz and Willard, 1978) or 20, 37, and 55\% sucrose in $5 \mathrm{mM}$ Tris $\cdot \mathrm{HCl}, \mathrm{pH} 7.4$. Membranes were then centrifuged for $7.8 \times 10^{6} \mathrm{~g}_{\mathrm{av}}$ min (Beckman SW 41, Ti, 26,500 rpm, $90 \mathrm{~min}$ ). The bottom of the tube was punctured, and the interfaces were collected directly into ultracentrifuge tubes. The contents were diluted with icecold $5 \mathrm{~mm}$ Tris and $5 \mathrm{~mm}$ Tris $/ 0.32 \mathrm{M}$ sucrose with mixing, and the membranes were pelleted as above for total particulate material. Mem-

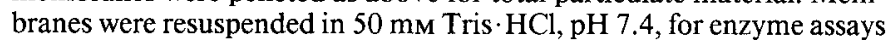
or in water for lyophilization and subsequent electrophoresis.

\section{Enzyme assays}

Standard procedures were used to quantify ouabain-sensitive Na-K AT Pase (EC 3.6.1.4, Medzihradsky et al., 1971; Breer and Knipper, 1985), succinate dehydrogenase (EC 1.3.99.1, Porteous and Clark, 1965; Breer and Knipper, 1985), and protein (Bradford, 1976).

\section{Electrophoresis}

2DE was performed using nonequilibrium $\mathrm{pH}$ gradient electrophoresis (NEPHGE; O'Farrell et al., 1977). Tissue was solubilized directly in lysis buffer (O'Farrell et al., 1977) and then centrifuged at $8000 \times g$ for $5 \mathrm{~min}$. When samples were to be compared within an experiment, equal amounts of radioisotope (cpm) were loaded on gels. Radioactivity was determined by adding $1 \mu \mathrm{l}$ aliquots of samples to $200 \mu \mathrm{l}$ of $0.1 \% \mathrm{BSA}$; the mixture was precipitated with $8 \%$ tricholoroacetic acid. After rinsing and drying, precipitates were solubilized in Protosol (DuPont, NEN Products) prior to addition of liquid scintillation cocktail. Ampholytes (LKB Corp., Uppsala, Sweden) were present in the acrylamide mixture of the first dimension in the following proportions: $0.04 \% 3.5 / 10,0.11 \%$ $5 / 7$, and $0.05 \% 7 / 9$. The first dimension was run in disposable $100 \mu \mathrm{l}$ pipettes; gels were removed and equilibrated for the second dimension according to Garrels (1979). SDS-PAGE was carried out according to Laemmli (1970) in slabs $(20.3 \mathrm{~cm}$ high $\times 33 \mathrm{~cm}$ wide) of polyacrylamide (13.5\% total, 37:1, monomer: bis). Each SDS gel was loaded with 4 first-dimension gels; stacking gels were not used. Following electrophoresis, gels were fixed in methanol : water : acetic acid (50:40:10, vol) and then stained by a silver procedure (Oakley et al., 1980, or Morrissey, 1981) or prepared for fluorography (Bonner and Laskey, 1974) with the use of EN ${ }^{3}$ HANCE (Du Pont, NEN Research Products) according to the manufacturer's instructions. Radioactive gels were exposed to X-ray film (Kodak X-Omat AR film) that had been "preflashed" (Laskey and Mills, 1975). Exposures lasted $1-12$ weeks at $-80^{\circ} \mathrm{C}$.

Fluorograms were scanned with a Bioimage Visage (Kodak, Inc.) system to yield numerical values of spot intensities that were normalized to the summed intensities of all spots on the fluorogram. The normalized intensities of individual spots were compared within or between fluo- 

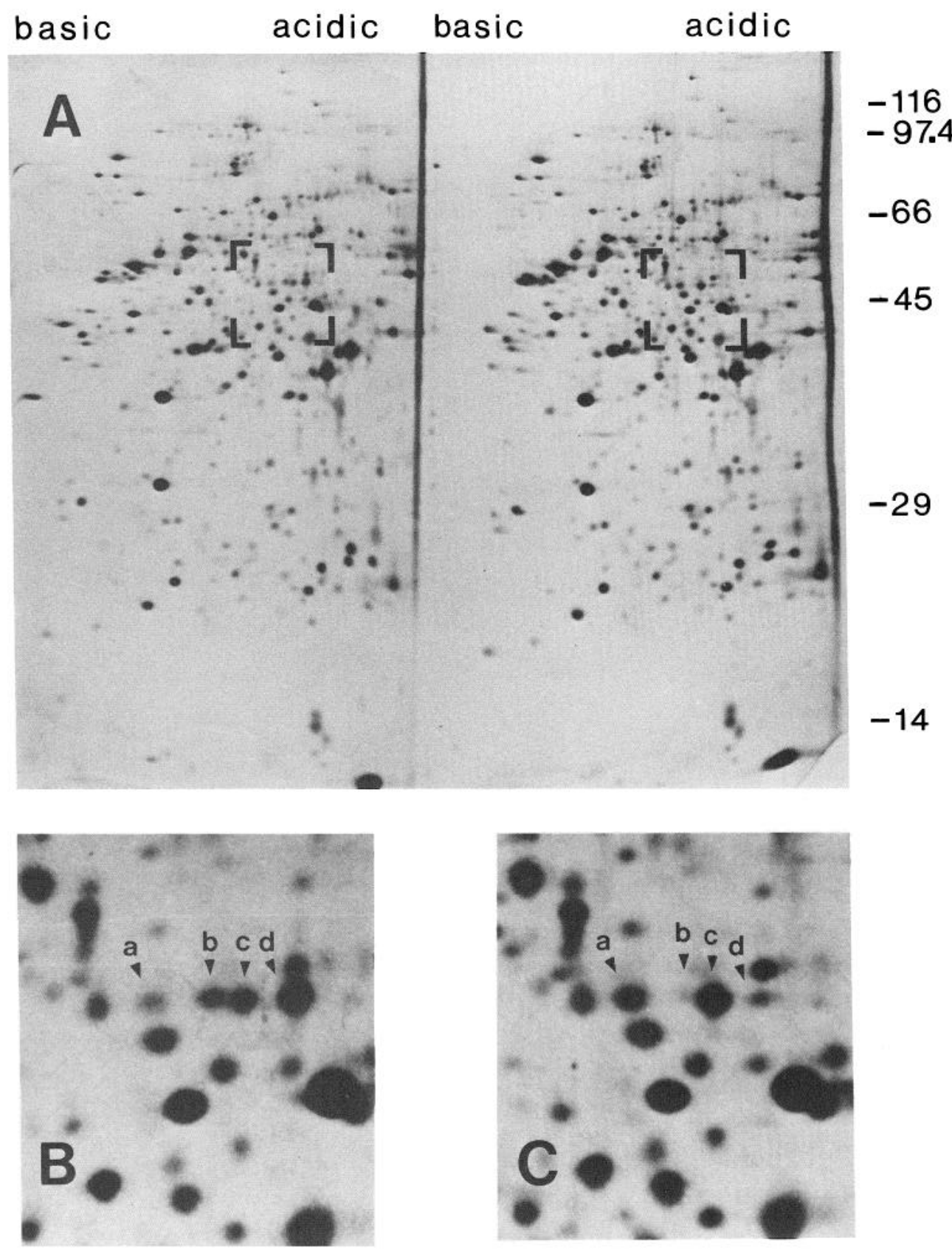

Figure 1. NEPHGE-2DE (this and all other gels) of AN and AL tissue from stage 11 developing adults; proteins visualized by silver staining. $A$, left: male; right: female; NEPHGE gels were run side-by-side on an SDS gel. $B$ (male) and $C$ (female), Details of appropriate $49 \mathrm{kDa}$ regions from $A$ shown in brackets. The female sample contained ca. $50 \%$ more protein than that in the male sample. The $49 \mathrm{kDa}$ polypeptides are designated $49 a, b, c$, and $d$ in order of decreasing mobility on NEPHGE, i.e., apparently increasing acidity. The positions of molecular-weight markers (from a separate gel) are indicated to the right in $A$ and are, from top to bottom (in $\mathrm{kDa}$ ): $\beta$-galactosidase, 116 ; phosphorylase B, 97.4; BSA, 66; ovalbumin, 45; carbonic anhydrase, 29; lysozyme, 14. rograms to obtain information about the relative accumulation of ${ }^{35} \mathrm{~S}$ methionine in individual polypeptides.

\section{Results}

Initial experiments using SDS-PAGE alone or with isoelectric focusing (O'Farrell, 1975) in 2DE failed to reveal sexually dimorphic proteins in extracts of ANs of developing moths. Because at least some basic proteins did not enter the gels, we repeated the experiments using NEPHGE-2DE. This procedure allowed us to detect a greater number of polypeptides in silverstained gels; in addition, when comparing extracts of male and female ANs, we found significant quantitative differences among certain polypeptides.

The patterns of stained proteins obtained with extracts of combined ANs and ALs from developing males and females are nearly identical (Fig. $1 A$ ). Nevertheless, we could reproduc- ibly detect a group of 4 polypeptides, all with apparent molecular weights of $49 \mathrm{kDa}$ and apparently similar charge, that differ quantitatively in male and female ANs and ALs (Fig. 1, $B, C$ ). These polypeptides are designated $49 \mathrm{a}, 49 \mathrm{~b}, 49 \mathrm{c}$, and $49 \mathrm{~d}$ in order of increasing acidity (left to right in the photographs). As can be seen in Figure $1 B$, polypeptides $49 \mathrm{~b}$ and $49 \mathrm{~d}$ are enriched in male ANs and ALs, while $49 a$ and $49 c$ are enriched in female ANs and ALs. These differences in the stainable polypeptides can be detected at least as early as stage $5 / 6$, the youngest animals used in these experiments. When extracts of ANs and ALs were electrophoresed separately, we did not detect significant differences in the relative amounts of these polypeptides.

Axons in the AN are bundled in fascicles surrounded by glial-like cells (Sanes and Hildebrand, 1976b). These ensheathing cells contribute proteins to the stained pattern and could conceivably account for some of the observed sexual dimorphism. 


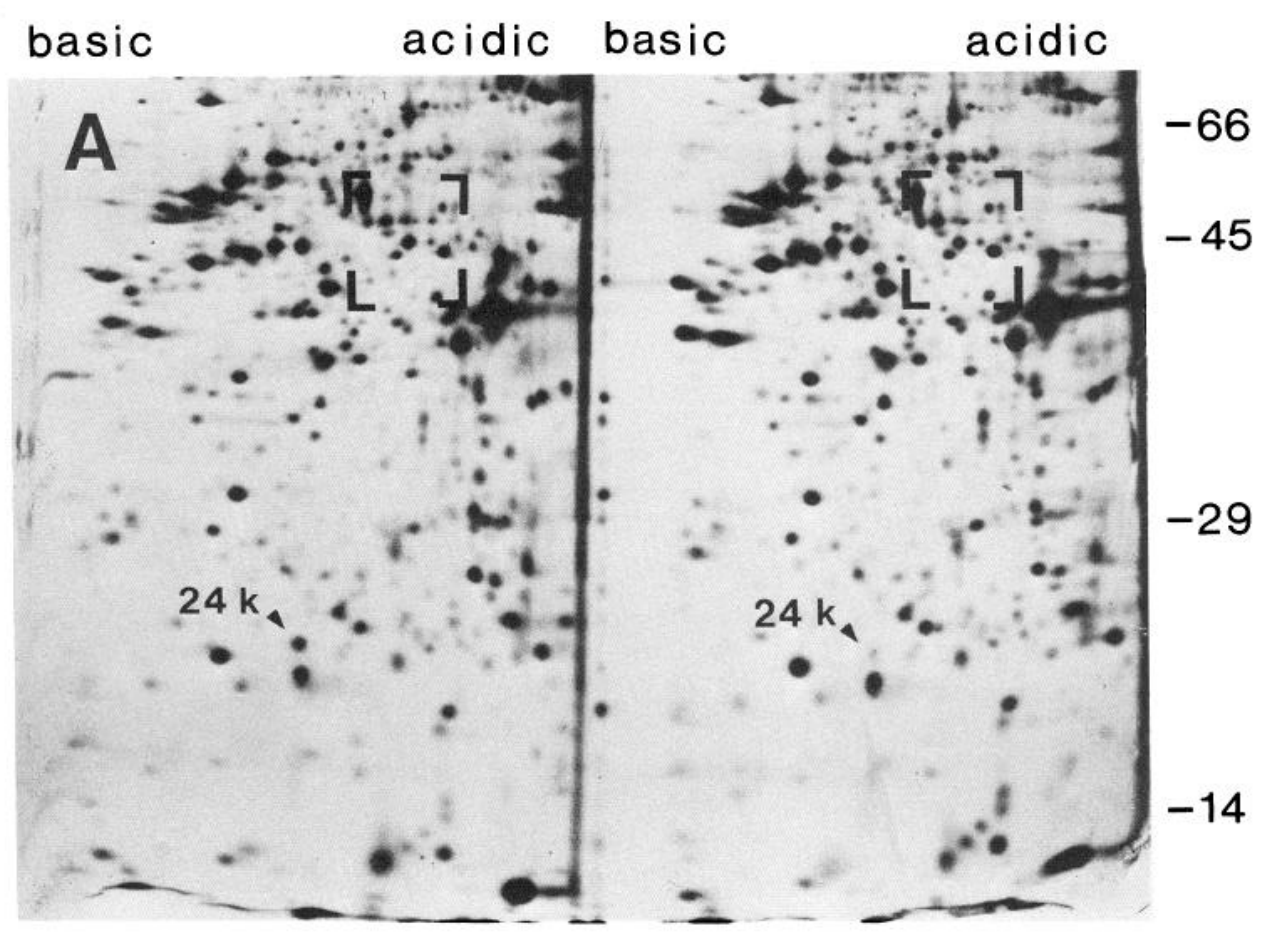

Figure 2. Fluorogram after 2DE of extracts of in situ labeled ANs and ALs of 2 males and 2 females. ${ }^{35}$ S-Methionine was injected into the distal third of antennae of stage 9 male and female developing adults. ANs and ALs were removed $2.5 \mathrm{~d}$ later, at which time the animals had developed to stage 11. $A$, Male (left) and female (right) extracts, run side-by-side in the second-dimension (SDS) gel. Details of the $49 \mathrm{kDa}$ region are shown for the male $(2 B)$ and the female $(2 C)$. Molecular-weight markers (to the right) as described for Figure 1.
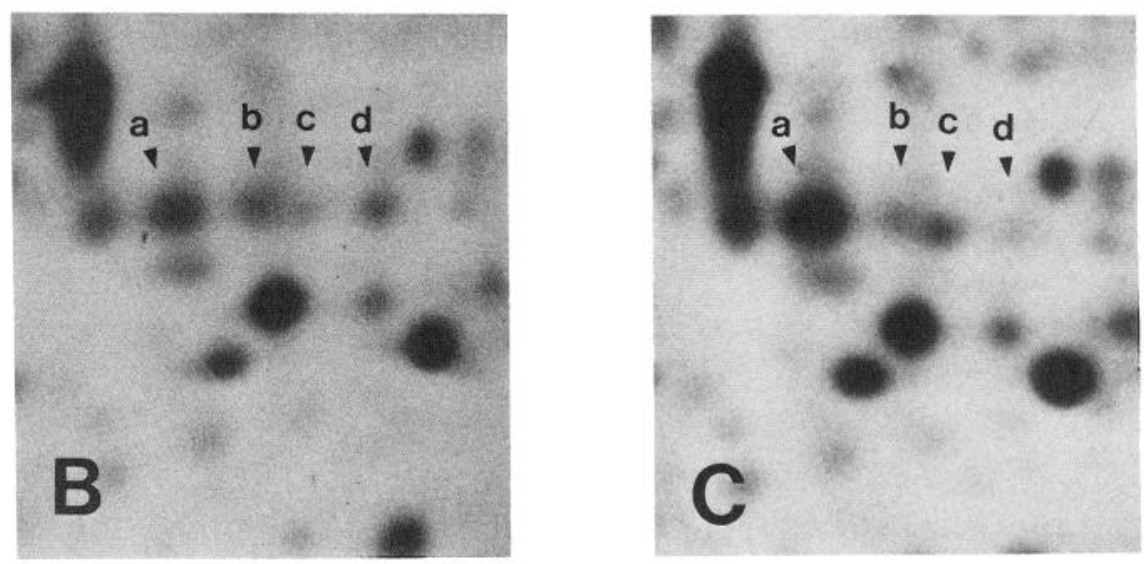

To test this possibility and to sample the complement of proteins synthesized and transported at discrete stages of development, we labeled proteins by injection of ${ }^{35} \mathrm{~S}$-methionine into the antennae of developing moths. The ipsilateral $\mathrm{AL}$ and the intracranial portion of the corresponding AN were removed 0.5-3 $\mathrm{d}$ after the injection. The results of a $2.5 \mathrm{~d}$ experiment are shown in Figure 2. The $49 \mathrm{kDa}$ proteins are present in the fluorograms from both male and female ANs and ALs (Fig. 2 B, C); in addition, their patterns of relative abundance are qualitatively similar to those in the stained gels (cf. Fig. 1, $B, C$ ).

The fluorograms reveal an additional polypeptide, of $24 \mathrm{kDa}$ apparent molecular weight, that is enriched in extracts of male ANs and ALs (Fig. 2A). Because silver-stained gels only occasionally show a very faint spot in this position, it seems that this protein either is present in very small amounts relative to others or is refractory to staining by our methods.

Our initial findings showed that ANs contain 5 polypeptides, synthesized in developing moths and differing quantitatively in males and females. These polypeptides apparently are synthe- sized in sensory cell bodies in the antenna and move to the AN and AL by axonal transport. Alternatively, some of the polypeptides in the fluorograms might have been produced in the gliallike cells of the AN or cells in the AL, incorporating free ${ }^{35} \mathrm{~S}$-methionine that had reached the AN or AL. We attempted to address this possibility by examining the complement of polypeptides synthesized by ANs and ALs from stage 7-8 males in short-term organ culture (see Materials and Methods). While many proteins found in the "axonal transport" fluorograms were also found in the "organ culture" fluorograms, the overall patterns were very different (cf. Fig. 3, $A, B$ ), supporting our conclusion that injections into the antenna labeled only transported proteins. By overlapping fluorograms we found spots in the "organ culture" fluorograms corresponding to all $49 \mathrm{kDa}$ polypeptides, although their relative labeling seemed not to correspond to either the male or the female pattern. In addition, we found a spot corresponding to the $24 \mathrm{kDa}$ polypeptide, but its intensity in "organ-culture" fluorograms was very low, particularly with respect to the total level of protein biosynthesis in 

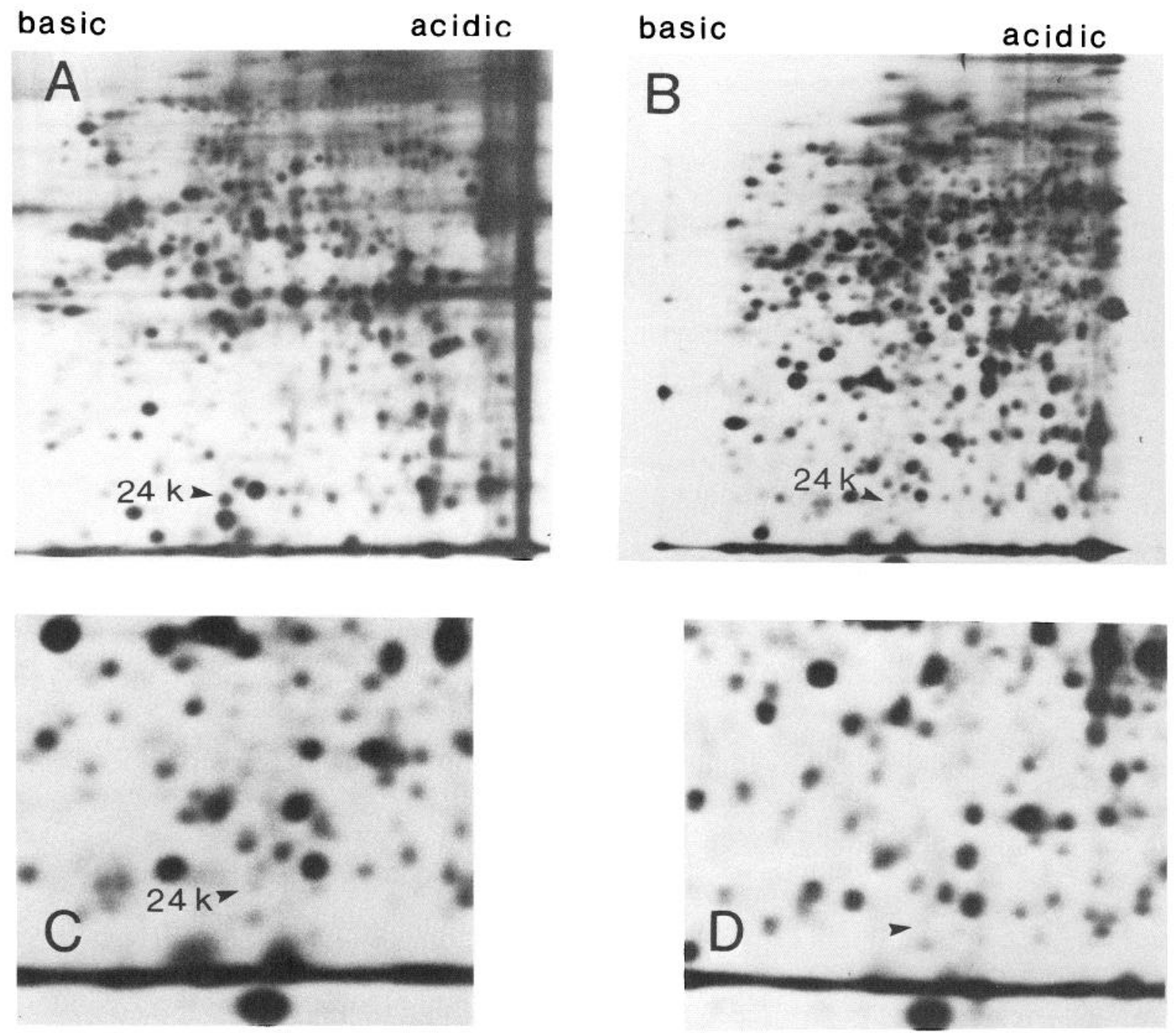

Figure 3. Fluorograms comparing the biosynthetic activity of ANs and ALs in vitro with the complement of radiolabeled polypeptides reaching the AN by axonal transport. $A$, Fluorogram after in situ labeling of stage $7 / 8$ males $2.0 \mathrm{~d}$ before removal of ANs and ALs. This gel is provided for comparison with others in this figure. $B$. Fluorogram of AN extract from stage $7 / 8$ males after in vitro labeling of whole brains (see Materials and Methods). $C$, Detail of the region in $B$ containing the $24 \mathrm{kDa}$ polypeptide. $D$, Detail of a fluorogram from an extract of $\mathrm{AL}$ after in vitro labeling.

ANs in vitro (Fig. 3, B, C). Similar fluorograms prepared from $\mathrm{AL}$ extracts also reveal synthesis of the $49 \mathrm{kDa}$ polypeptides; we could not, however, detect the $24 \mathrm{kDa}$ polypeptide in these preparations (Fig. $3 D$ ). Thus, the in vitro studies show that the relative amounts of the $49 \mathrm{kDa}$ polypeptides reaching the $\mathrm{AL}$ by axonal transport are markedly greater than those arising by local synthesis. Moreover, the $24 \mathrm{kDa}$ polypeptide may be completely absent (AL) or present in only minute amounts (AN) in preparations monitoring local biosynthesis. We conclude that the 49 and $24 \mathrm{kDa}$ polypeptides revealed after in vitro labeling were proteins synthesized in antennal sensory neurons and transported through their axons in the AN toward their terminals in the AL.

Knowledge of the rates of transport of axonal polypeptides is helpful if inferences about their function are to be made. We therefore sought to determine the relative rates of transport of the 49 and $24 \mathrm{kDa}$ polypeptides by removing the ANs and ALs from animals at intervals of $0.5-3 \mathrm{~d}$ after the injections. Un- fortunately, this antennal preparation does not lend itself to absolute determinations of rates of axonal transport. Somata of antennal receptor cells are distributed along the entire length of the antennal flagellum. If radiolabeled amino acid injected focally into one annulus of the flagellum spreads to several other annuli, resolution of different transport classes of polypeptides is correspondingly decreased. Nevertheless, when the ANs and ALs are removed from animals 0.5 or $1 \mathrm{~d}$ after the injection, far fewer radiolabeled polypeptides are found than in the 2 or $3 \mathrm{~d}$ preparations (Fig. 4). Apparently, the more rapidly transported polypeptides account for the radiolabel in the 0.5 or 1 $\mathrm{d}$ extracts. Among these relatively rapidly transported species is the $24 \mathrm{kDa}$ polypeptide, which represents a greater proportion of the total label in the 0.5 or $1 \mathrm{~d}$ extracts than in 2 or $3 \mathrm{~d}$ extracts (Table 1). Of the $49 \mathrm{kDa}$ polypeptides, only $49 \mathrm{a}$ can be visualized at 24 or $36 \mathrm{hr}$ after injection. The other $49 \mathrm{kDa}$ polypeptides appear in the ANs and ALs at $48 \mathrm{hr}$, however, along with many other polypeptides not previously detected. 
Figure 4. Fluorogram after in situ labeling of stage $7 / 8$ males (left) and females (right). ANs and ALs were removed $24 \mathrm{hr}$ after injection of ${ }^{35} \mathrm{~S}$-methionine. The $24 \mathrm{kDa}$ polypeptide represents a greater fraction of the total label than in Figure 2, which includes more slowly transported polypeptides. Polypeptide 49 a is very lightly labeled, while the other $49 \mathrm{kDa}$ polypeptides are not detectable.

\section{basic \\ acidic basic \\ acidic}

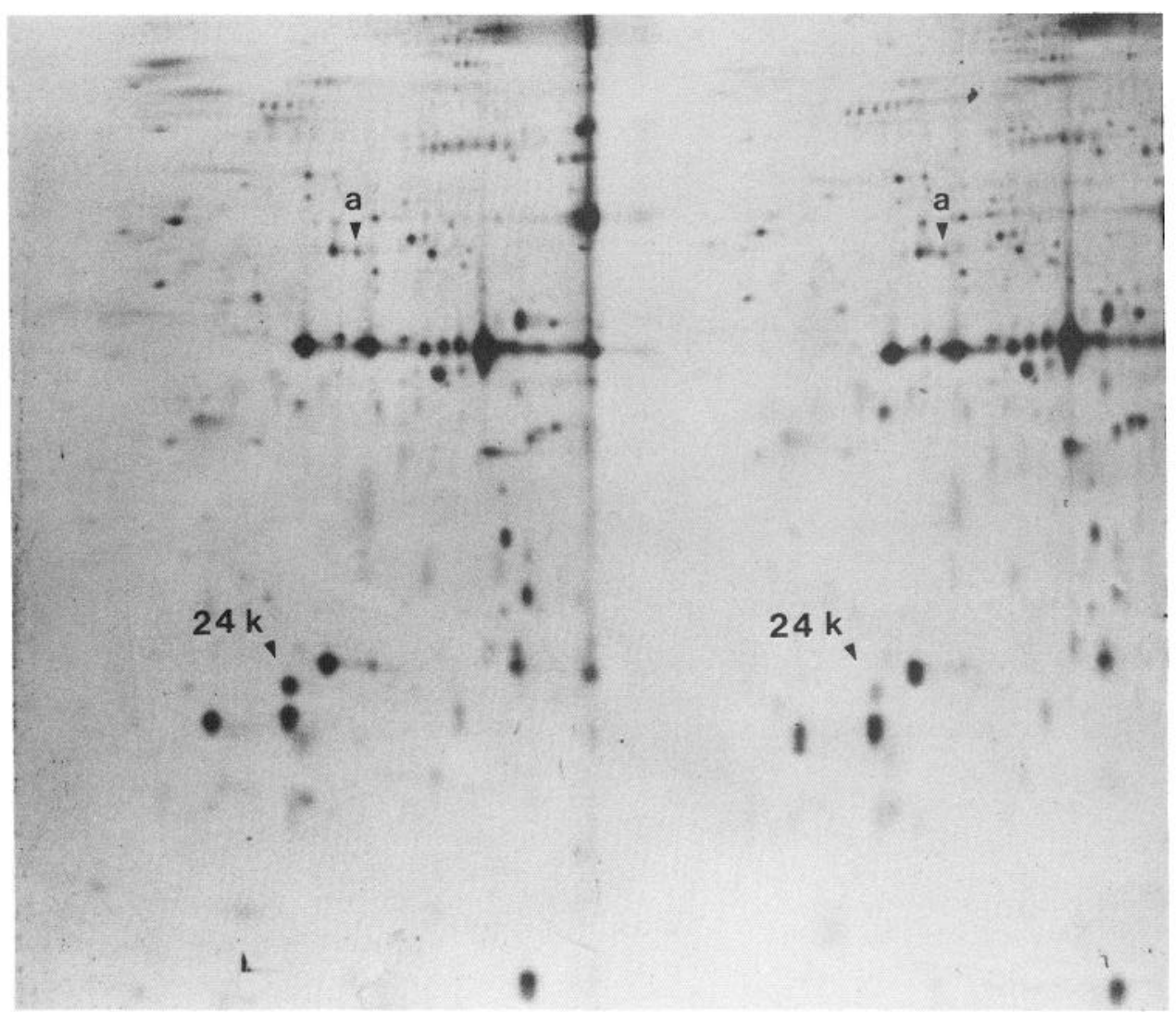

Thus, the $24 \mathrm{kDa}$ polypeptide belongs to a class of rapidly transported polypeptides, and the bulk of the $49 \mathrm{kDa}$ polypeptides belongs to a different, more slowly transported class.

An estimate of the relative rates of synthesis of the 24 and $49 \mathrm{kDa}$ polypeptides in males and females was obtained after scanning the fluorograms from extracts prepared $2.5 \mathrm{~d}$ postinjection (Fig. 5). The 49b and 49d polypeptides are enriched ca. 3.5 - and 6.7 -fold, respectively, in males, while $49 \mathrm{a}$ and $49 \mathrm{c}$ are enriched ca. 1.2- and 2.4-fold in females. The enrichment of 49a is ca. 4-fold when total protein is examined with silverstained gels (data not shown). Small enrichments in the synthesis and transport of specific polypeptides may be amplified by factors controlling turnover of protein in axons and nerve termi-

\begin{tabular}{|c|c|}
\hline Hours post injection & $\begin{array}{l}\text { Percentage } 24 \mathrm{kDa} \\
\text { polypeptide }^{a}\end{array}$ \\
\hline 24 & $1.73 \pm 0.10^{b}$ \\
\hline 48 & 0.99 \\
\hline 63 & 0.45 \\
\hline 48 (stage 16 ) & 0.15 \\
\hline
\end{tabular}

${ }^{a}$ Value reported is the percentage of the total optical density in the gel represented by the $24 \mathrm{kDa}$ polypeptide. Animals were stage $7 / 8$ at time of injection, except as indicated.

${ }^{\text {h}}$ Mean and range of separate determinations for AN and AL. Other values were obtained from extracts of combined AN and AL. nals. Synthesis and transport of the $24 \mathrm{kDa}$ polypeptide are approximately 9 -fold enriched in males; as discussed above, this polypeptide cannot be detected readily in stained gels.

The 49 and $24 \mathrm{kDa}$ polypeptides are synthesized and transported toward the AL at least as early as stage $5 / 6$ of adult development. Moreover, the sexual dimorphism in their syntheses ( 49 and $24 \mathrm{kDa}$ ) and accumulation ( $49 \mathrm{kDa}$, see above) are demonstrable at this stage. The patterns observed at this time in adult development are preserved, at least qualitatively, through stage 13 (data not shown). At stage 18, the day of emergence of the adult moth, the $49 \mathrm{kDa}$ polypeptides are all present in both males and females, but the patterns of enrichment that are obvious at earlier stages are no longer readily apparent (Fig. 6). Biosynthesis and transport of these polypeptides continue in males at this late stage in development (Fig. 7), but it is evident that the contribution of $49 \mathrm{~d}$ is reduced. Synthesis and/or transport of the $24 \mathrm{kDa}$ polypeptide is greatly reduced in stage 16 males (Fig. 7; cf. Fig. 3A). The change in this polypeptide's relative contribution (Table 1) appears to be part of a broad change in the pattern and relative quantities of transported polypeptides during the course of adult development.

If the 24 and $49 \mathrm{kDa}$ polypeptides are to be considered candidates for a role in development, it is important to determine their distributions among subcellular fractions. Accordingly, we prepared total particulate and soluble fractions from ANs and ALs for 2DE (see Materials and Methods). All $49 \mathrm{kDa}$ polypeptides are found in the particulate fractions (Fig. 8A). The soluble fraction (Fig. $8 B$ ) is greatly enriched in $49 \mathrm{c}$ and $49 \mathrm{~d}$, 
Synthesis of sexually dimorphic polypeptides

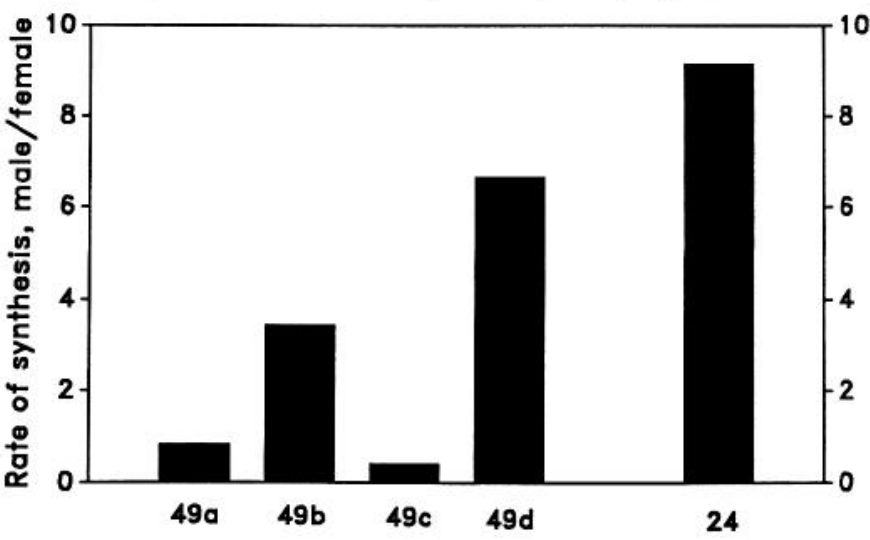

Figure 5. The 24 and $49 \mathrm{kDa}$ polypeptides were quantified from X-ray film after fluorography, and normalized ratios (see Materials and Methods) are reported. Data are from experiment reported in Figure 2.

while $49 \mathrm{a}$ and $49 \mathrm{~b}$ are almost undetectable. The $24 \mathrm{kDa}$ polypeptide is found in the particulate fraction but not in the soluble fraction.

We have extended these findings by analyzing the total-membrane fraction from ANs and ALs on sucrose gradients. In a preliminary study designed to determine the distribution of marker enzymes, we fractionated total membranes from the brains of stage $7 / 8$ males on discontinuous gradients consisting of $20,26,31,37,45$, and 55\% sucrose (see Materials and Methods). Ouabain-inhibitable $\mathrm{Na} / \mathrm{K}$-dependent ATPase activity (ATPase) is enriched at the surfaces of 26 and 31\% sucrose, while most of the succinate dehydrogenase activity $(\mathrm{SDH})$ passes through 37 and $45 \%$ sucrose and is enriched at the surface of $55 \%$ sucrose. On the basis of these findings, we chose to fractionate the less abundant tissue from animals receiving injections of ${ }^{35} \mathrm{~S}$-methionine with step gradients containing 20,37, and $55 \%$ sucrose. The distributions of ATPase, SDH, and the $24 \mathrm{kDA}$ polypeptide are shown in Figure 9. The enrichment of SDH in the "mitochondrial" fraction $(37 / 55)$ is ca. 7 -fold, while the ouabain-sensitive ATPase is only slightly enriched in the lighter membrane fraction (20/37). Nevertheless, the $24 \mathrm{kDa}$ polypeptide is ca. 10 -fold enriched in the $20 / 37$ fraction; this fraction is likely to include plasma and/or microsomal membranes. The $24 \mathrm{kDa}$ polypeptide is not associated with the heavier, "mitochondrial" fraction.

\section{Discussion}

The antennal flagellum of both male and female $M$. sexta comprises about 80 annuli. While the 2 basal segments of the antenna (scape and pedicel) contain numerous mechanosensory sensilla, the sensilla in the flagellum are believed to be predominantly chemosensory. Approximately 56,000 sensilla basiconica in male M. sexta (Sanes and Hildebrand, 1976a) closely resemble the most abundant sensilla in females. Sensory neurons innervating sensilla of this class respond to plant-derived volatile substances. In addition, each antenna of male $M$. sexta contains ca. 43,000 sensilla trichodea (Sanes and Hildebrand, 1976a) whose sensory cells respond to female pheromones (Kaissling et al., 1989). These receptor cells contribute $25-33 \%$ of the axons in the $\mathrm{AN}$ of the male. Thus, although the AN contains axons of several different functions, comparison of the proteins in male
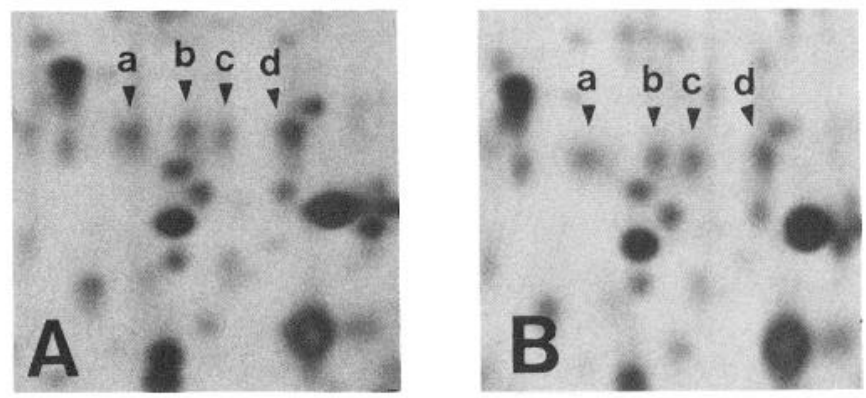

Figure 6. Detail of silver-stained gels after 2DE of AN and AL tissue of stage 18 males (left) and females (right). All $49 \mathrm{kDa}$ polypeptides are present in both sexes. In mature animals there are only slight enrichments of the kind readily detectable in developing animals.

and female ANs should reveal candidates for male-specific functions.

The patterns of polypeptides extracted from ANs and ALs of developing males and females and visualized after 2DE were nearly identical. Using NEPHGE-2DE, we identified 2 classes of polypeptides, distinguished on the basis of apparent molecular weight, in which differences between males and females are reproducibly demonstrated. One class contains four $49 \mathrm{kDa}$ polypeptides of similar charge, and the second consists of a single $24 \mathrm{kDa}$ polypeptide.

These 2 classes of polypeptides also differ in apparent rates of axonal transport. The patterns of labeling of different groups of polypeptides extracted from ANs on successive days following injection of ${ }^{35} \mathrm{~S}$-methionine provide evidence for at least 2 classes of rapidly transported proteins. Newly synthesized 24

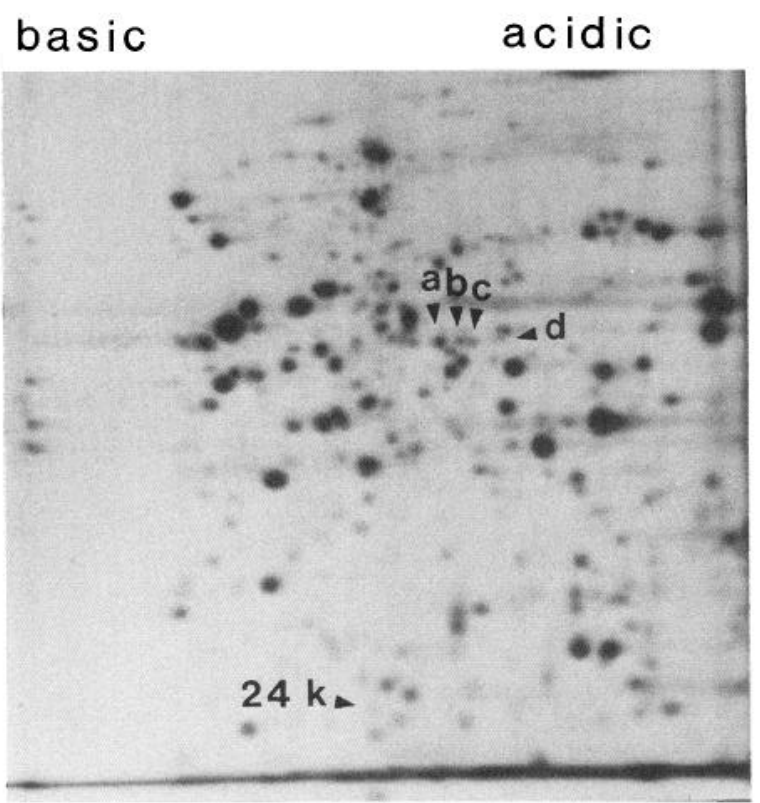

Figure 7. Fluorography after 2DE of ANs and ALs from stage 18 male that had received an antennal injection of ${ }^{35} \mathrm{~S}$-methionine at stage 16 $(50 \mathrm{hr}$ earlier). Fewer proteins are heavily labeled in these mature animals than at earlier developmental stages. Synthesis and/or transport of the $24 \mathrm{kDa}$ polypeptide is greatly reduced (cf. Fig. $3 A$ ). $49 \mathrm{a}, 49 \mathrm{~b}$, and $49 \mathrm{c}$ are still labeled, while synthesis of $49 \mathrm{~d}$ is apparently reduced (cf. Fig. 2B). 
basic

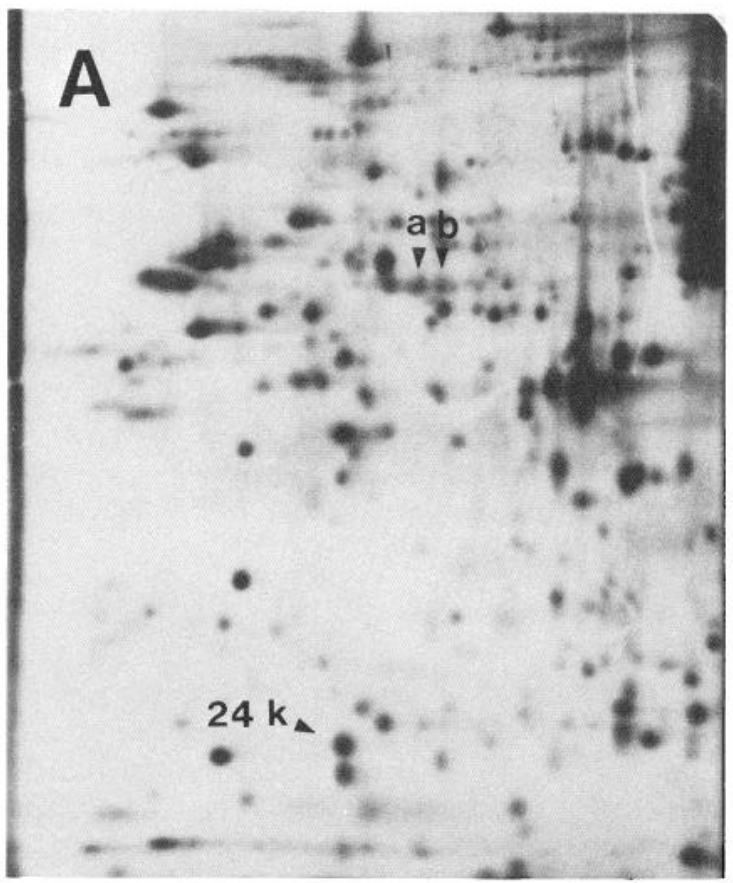

basic acidic

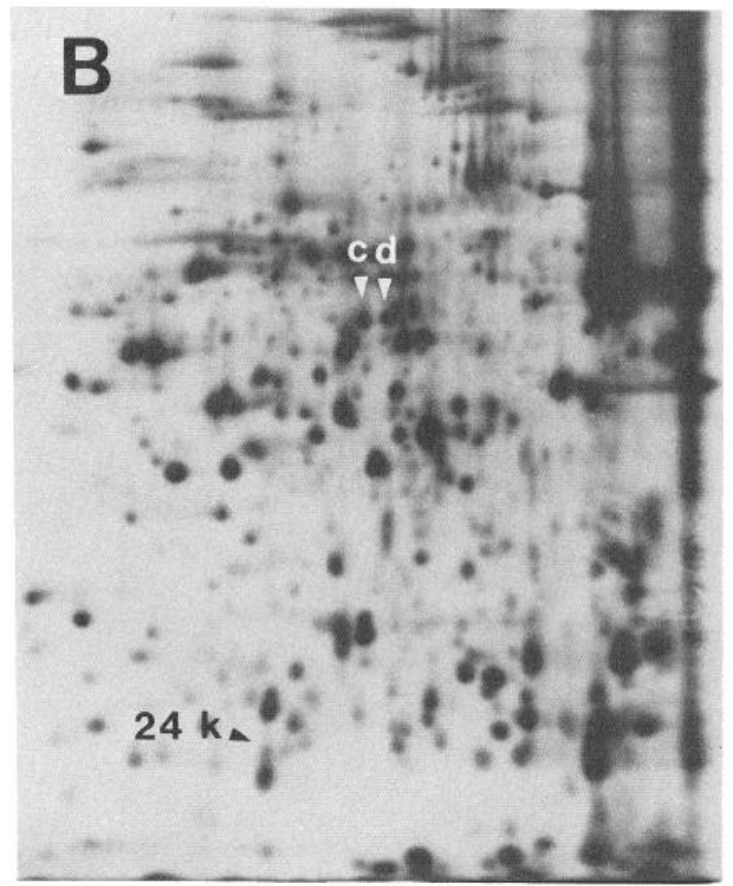

Figure 8. Particulate $(A)$ and soluble $(B)$ fractions were subjected to $2 \mathrm{DE}$ and fluorography. The $24 \mathrm{kDa}$ polypeptide is restricted to the particulate fraction; there is a slight "tailing" of a polypeptide running immediately below the expected location of the $24 \mathrm{kDa}$ polypeptide. The $49 \mathrm{kDa}$ polypeptides are present in both the particulate and soluble fractions. 49a and 49b (black arrowheads) are enriched in the particulate fraction; $49 \mathrm{c}$ and $49 \mathrm{~d}$ (white arrowheads) are enriched in the soluble fraction.

kDa polypeptide appears in the AN $12 \mathrm{hr}$ after injection of ${ }^{35} \mathrm{~S}-$ methionine into the antenna $20 \mathrm{~mm}$ distal to the intracranial portion of the AN analyzed in these studies. At this time, the majority of the labeled proteins are found as a series of spots in arcs at the top of the gel, suggestive of glycoproteins. Among the $49 \mathrm{kDa}$ polypeptides, a small amount of $49 \mathrm{a}$ was detected in the $24 \mathrm{hr}$ fluorograms, but the bulk arrives at $48 \mathrm{hr}$ along with the other $49 \mathrm{kDa}$ polypeptides. They arrive in the AN at the same time as many other labeled proteins (cf. Figs. 2 and

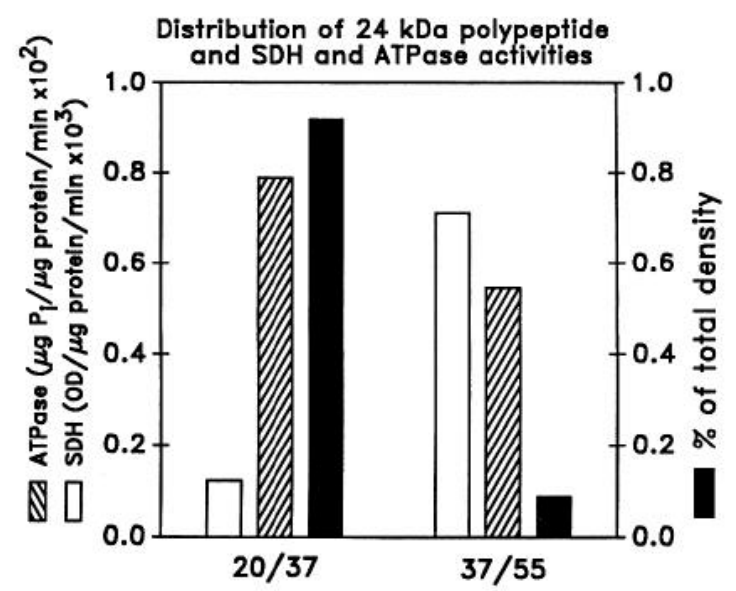

Figure 9. Membranes were collected at the interfaces of $20-37 \%(20 /$ $37)$ and $37-55 \%(37 / 55)$ sucrose. Aliquots were assayed for SDH and ouabain-inhibitable ATPase activities, while additional aliquots were subjected to $2 \mathrm{DE}$ and fluorography for quantification of the $24 \mathrm{kDa}$ polypeptide. $\mathrm{P}_{\mathrm{i}}$, phosphate.
4). The majority of these proteins arrives $36-48 \mathrm{hr}$ after injection, perhaps as a wave-front comprising a distinct class of transported proteins.

The sexually dimorphic patterns of the 24 and $49 \mathrm{kDa}$ polypeptides are most pronounced during early development, beginning no later than stages $5 / 6$ of adult development and extending at least until stage 13 . Sensory axons begin to reach the $\mathrm{AL}$ at stage 3 and have begun to grow into the AL neuropil by stage 4 (Camazine and Hildebrand, 1979). Formation of AL glomeruli (including the MGC) proceeds from stage 4 and is complete by stage 13 (Tolbert et al., 1983; Schneiderman, 1984). Thus, elevated synthesis of polypeptides $24 \mathrm{kDa}$ and $49 \mathrm{~b}$ and $49 \mathrm{~d}$ in males is demonstrable at a time in development coincident with the growth of sensory axons and their participation in formation of glomerular synaptic neuropil. The sexual dimorphism in the expression of the $24 \mathrm{kDa}$ polypeptide ends late in development; by stage 16, its synthesis and transport are reduced to nearly undetectable levels. In this respect, the 24 $\mathrm{kDa}$ polypeptide resembles the growth-associated proteins demonstrated in axons arising from toad and rabbit retinal ganglion cells (Skene and Willard, 1981a, b), one of which was reported to be either $24 \mathrm{kDa}$ (toad) or $23 \mathrm{kDa}$ (rabbit) in molecular weight. The $24 \mathrm{kDa}$ polypeptide described in this report appears to be synthesized only at very low levels or not at all by CNS tissue (AL) or fragments of AN containing glia but not the somata of sensory cells. Of the $49 \mathrm{kDa}$ polypeptides in $M$. sexta, $49 \mathrm{~d}$ shows a significant decline in incorporation of radioisotope late in development in males; 49a, 49b, and 49c are still readily detectable when labeling is carried out $2 \mathrm{~d}$ before emergence of the adult moth. The stained gels reveal much less sexual dimorphism in these polypeptides than is demonstrable early in 
development. The patterns in the stained gels suggest that females accumulate $49 \mathrm{~b}$ and $49 \mathrm{~d}$ late in development, reducing the sexual dimorphism in the staining patterns.

The sexually dimorphic polypeptides discussed in this report are apparently different from the male-specific antigen detected in the sensory cells of the trichoid sensilla of $M$. sexta with a monoclonal antibody (Hishinuma et al., 1988a). This antigen, termed male olfactory specific antigen (MOSA), is detectable in male sensory cells only late in development (Hishinuma et al., 1988b). The fact that we have not detected a protein in the gel patterns from ANs and ALs of mature moths that is a candidate to be MOSA may be due to limitations of $2 \mathrm{DE}$. It is also possible that modifications by male-specific sensory cells of a protein also present in non-sexually-dimorphic cells alters its immunogenicity to produce MOS $\Lambda$ without appreciably changing its electrophoretic properties.

A number of polypeptides not discussed in this report decline in synthesis and/or transport late in development with time courses similar to that of the $24 \mathrm{kDa}$ polypeptide. While we have not detected sexually dimorphic expression of these polypeptides, they are candidates for a role in the development of synaptic interactions in the "ordinary" glomeruli of the AL.

The firm association of the $24 \mathrm{kDa}$ polypeptide with the particulate fraction and the enrichment of that polypeptide in plasma membrane/microsomal fractions are consistent with its rapid rate of axonal transport. These findings support the possible involvement of the $24 \mathrm{kDa}$ polypeptide in developmental events leading to the formation of the MGC. The subcellular distribution of the $49 \mathrm{kDa}$ polypeptides is predicted, to some extent, by their apparent charge as revealed in NEPHGE: the more acidic $49 \mathrm{c}$ and $49 \mathrm{~d}$ are greatly enriched in the soluble fractions, while $49 a$ and $49 b$ are found in the particulate fractions. It is not yet known if the $49 \mathrm{kDa}$ polypeptides are related to each other, as suggested by the apparent identity of their molecular weights and the similarity of their charges (mobility on NEPHGE gels).

Because of their sexually dimorphic, pheromone-sensitive sensory cells, males have more afferent axons in their AN than do females. If the higher rate of synthesis of the $24 \mathrm{kDa}$ polypeptide is attributable to the male-specific sensory cells, then its enrichment in these cells would be significantly greater than 9-fold, which was determined for whole ANs. The enrichment of $49 \mathrm{~b}$ and $49 \mathrm{~d}$ in males could be accounted for in a similar way. The enrichment of $49 \mathrm{a}$ in females, while ca. 4-fold on stained gels, is only $20 \%$ on the fluorograms; $49 \mathrm{c}$ appears to be similarly enriched in females ANs upon quantification in stained gels $(2.6 \times)$ and fluorograms $(2.4 \times)$. It is difficult to explain the different quantitative enrichments in females of $49 \mathrm{a}$ and $49 \mathrm{c}$ solely on the basis of a depletion in male ANs. It is possible that these proteins are subject to different rates of turnover.

The functions of the 49 and $24 \mathrm{kDa}$ polypeptides are unknown. Identification of molecular differences in the proteins synthesized by male and female antennal receptor cells is, nevertheless, compelling in its implications for the study of neural development. Male-specific, functionally specialized neuropil structures can develop in AI s of either sex, but only when some cue from sensory afferents of the male antenna is provided at close range (Schneiderman et al., 1982). Moreover, the male AL has ca. 30 more nerve cell bodies than the female $\mathrm{AL}$ in the group of somata known to contain male-specific MGC projection neurons (Matsumoto and Hildebrand, 1981; Christensen and Hildebrand, 1987; Homberg et al., 1988). It seems likely that axons from trichoid sensilla influence these neurons or others common to both sexes to form the MGC. The accessibility of the developing peripheral and central elements of the moth olfactory system provides an unusual opportunity to investigate the roles of specific polypeptides in directing the development of a sexually dimorphic neuropil.

\section{References}

Arnold, A. P., and R. A. Gorski (1984) Gonadal steroid induction of structural sex differences in the central nervous system. Annu. Rev. Neurosci. 7: 413-442.

Bell, R. A., and F. A. Joachim (1976) Techniques for rearing laboratory colonies of tobacco hornworms and pink bollworms. Annu. Ent. Soc. Am. 69: 365-373.

Bonner, W. M., and R. A. Laskey (1974) A film detection method for tritium-labelled proteins and nucleic acids in polyacrylamide gels. Eur. J. Biochem. 46: 83-88.

Bradford, M. M. (1976) A rapid and sensitive method for the quantitation of microgram quantities of protein utilizing the principle of protein-dye binding. Anal. Biochem. 72: 248-254.

Breer, H., and M. Knipper (1985) Synaptosomes and neuronal membranes from insects. In Neurochemical Techniques in Insect Research, H. Breer and T. A. Miller, eds., pp. 125-155, Springer-Verlag, Berlin.

Camazine, S. M., and J. G. Hildebrand (1979) Central projections of antennal sensory neurons in the antennal lobes of the moth Manduca sexta. Soc. Neurosci. Abstr. 5: 155.

Christensen, T. A., and J. G. Hildebrand (1987) Male-specific, sex pheromone-selective projection neurons in the antennal lobes of the moth Manduca sexta. J. Comp. Physiol. 160: 553-569.

Garrels, J. I. (1979) Two-dimensional gel electrophoresis and computer analysis of proteins synthesized by clonal cell lines. J. Biol. Chem. 254: 7961-7977.

Grace, T. C. C. (1962) Fstahlishment of four strains of cells from insect tissues grown in vitro. Nature 195: 788-789.

Hildebrand, J. G. (1985) Metamorphosis of the insect nervous system: Influences of the periphery on the postembryonic development of the antennal sensory pathway in the brain of Manduca sexta. In Model Neural Networks and Behavior, A. Selverston, ed., pp. 129-148, Plenum, New York.

Hishinuma, A., S. Hockfield, R. McKay, and J. G. Hildebrand (1988a) Monoclonal antibodies reveal cell-type-specific antigens in the sexually dimorphic olfactory system of Manduca sexta. 1. Generation of monoclonal antibodies and partial characterization of the antigens. J. Neurosci. 8: 296-307.

Hishinuma, A., S. Hockfield, R. McKay, and J. G. Hildebrand (1988b) Monoclonal antibodies reveal cell-type-specific antigens in the sexually dimorphic olfactory system of Manduca sexta. 2. Expression of antigens during postembryonic development. J. Neurosci. 8: 308315.

Homberg, U., R. ^. Montague, and J. G. Hildebrand (1988) Anatomy of antenno-cerebral pathways in the brain of the sphinx moth Manduca sexta. Cell Tissue Res. 254: 255-281.

Kaissling, K.-E., J. G. Hildebrand, and J. H. Tumlinson (1989) Pheromone receptor cells in the male moth Manduca sexta. Arch. Insect Biochem. Physiol. (in press).

Kingan, T. G., and J. G. Hildebrand (1983) Sexually dimorphic expression of polypeptides in antennal sensory neurons of Manduca sexta. Soc. Neurosci. Abstr. 9: 835.

Laemmli, U. K. (1970) Cleavage of structural proteins during the assembly of the head of bacteriophage T4. Nature 227:680.

Laskey, R. A., and A. D. Mills (1975) Quantitative film detection of ${ }^{3} \mathrm{H}$ and ${ }^{14} \mathrm{C}$ in polyacrylamide gels by fluorography. Eur. J. Biochem. 56: $335-341$.

Lorenz, T., and M. Willard (1978) Subcellular fractionation of intraaxonally transported polypeptides in the rabbit visual system. Proc. Natl. Acad. Sci. USA 75: 505-509.

Matsumoto, S. G., and J. G. Hildebrand (1981) Olfactory mechanisms in the moth Manduca sexta: Response characteristics and morphology of central neurons in the antennal lobe. Proc. R. Soc. London [Biol.] 213: 249-277.

Medzihradsky, F., P. S. Nandhasri, V. Idoyaga-Vargas, and O. Z. Sellinger (1971) A comparison of the ATPase activity of the glial cell fraction and the neuronal perikaryal fraction isolated in bulk from rat cerebral cortex. J. Neurochem. 18: 1599-1603. 
Morrissey, J. H. (1981) Silver stain for proteins in polyacrylamide gels: A modified procedure with enhanced uniform sensitivity. Anal. Biochem. 117: 307-310.

Oakley, B. R., D. R. Kirsch, and N. R. Morris (1980) A simplified ultra-sensitive silver stain for detecting proteins in polyacrylamide gels. Anal. Biochem. 105: 361-363.

O'Farrell, P. H. (1975) High resolution two-dimensional electrophoresis of proteins. J. Biol. Chem. 250: 4007-4021.

O'Farrell, P. Z., H. M. Goodman, and P. H. O'Farrell (1977) High resolution two-dimensional electrophoresis of basic as well as acidic proteins. Cell 12: 1133-1142.

Portcous, J. W., and B. Clark (1965) The isolation and characterization of subcellular components of the epithelial cells of rabbit small intestine. Biochem. J. 96: 159-171.

Sanes, J. R., and J. G. Hildebrand (1976a) Structure and development of the antennae in a moth, Manduca sexta. Dev. Biol. 51: 282-299.

Sanes, J. R., and J. G. Hildebrand (1976b) Origin and morphogenesis of sensory neurons in an insect antenna. Dev, Biol. 51: 300-319.

Schneiderman, A. M. (1984) Postembryonic development of a sexually dimorphic sensory pathway in the central nervous system of the sphinx moth, Manduca sexta. Ph.D. thesis, Harvard University, Cambridge, MA.

Schneiderman, A. M., S. G. Matsumoto, and J. G. Hildebrand (1982) Trans-sexually grafted antennae influence development of sexually dimorphic neurones in moth brain. Nature 298: 844-846.

Shorr, R. G., A. Lyddiat, M. M. S. Lo, J. O. Dolly, and E. A. Barnard (1981) Acetylcholine receptor from mammalian skeletal muscle. Eur. J. Biochem. 116: 143-153.

Skene, J. H. P., and M. Willard (1981a) Changes in axonally transported proteins during axon regeneration in toad retinal ganglion cells. J. Cell Biol. 89: 86-95.

Skene, J. H. P., and M. Willard (1981b) Axonally transported proteins associated with axon growth in rabbit central and peripheral nervous system. J. Cell Biol. 89: 96-103.

Tolbert, L. P., S. G. Matsumoto, and J. G. Hildebrand (1983) Development of synapses in the antennal lobes of the moth Manduca sexta during metamorphosis. J. Neurosci. 3: 1158-1175. 